https://helda.helsinki.fi

\title{
Thermodynamic and kinetic approaches for evaluation of monoclonal antibody - Lipoprotein interactions
}

\section{Multia, Evgen}

2017

Multia , E , Sirén , H , Andersson , K , Samuelsson , J , Forssén , P , Fornstedt , T , Öörni , K , Jauhiainen , M \& Riekkola , M-L 2017 , ' Thermodynamic and kinetic approaches for evaluation of monoclonal antibody - Lipoprotein interactions ', Analytical Biochemistry , vol. 518 , pp. 25-34 . https://doi.org/10.1016/j.ab.2016.10.024

http://hdl.handle.net/10138/307958

https://doi.org/10.1016/j.ab.2016.10.024

cc_by_nc_nd

acceptedVersion

Downloaded from Helda, University of Helsinki institutional repository.

This is an electronic reprint of the original article.

This reprint may differ from the original in pagination and typographic detail.

Please cite the original version. 


\title{
Thermodynamic and kinetic approaches for evaluation of
} monoclonal antibody - lipoprotein interactions

\author{
Evgen Multiaa, Heli Siréna, Karl Andersson ${ }^{\text {b,c }}$, Jörgen Samuelssond, Patrik Forssén ${ }^{\text {, }}$ \\ Torgny Fornstedt ${ }^{d}$, Katariina Öörni ${ }^{\mathrm{e}}$, Matti Jauhiainen ${ }^{\mathrm{f}}$, Marja-Liisa Riekkola ${ }^{\text {* }}$ \\ ${ }^{a}$ Laboratory of Analytical Chemistry, Department of Chemistry, P.O. Box 55, FI-00014 University of \\ Helsinki, Finland.*E-mail: marja-liisa.riekkola@helsinki.fi \\ ${ }^{b}$ Ridgeview Instruments $A B / S E-74020$ Vänge, Sweden \\ ${ }^{c}$ Department of Immunology, Genetics and Pathology, Uppsala University, SE-75815 Uppsala, Sweden \\ ${ }^{d}$ Department of Engineering and Chemical Sciences, Karlstad University, SE-651 88 Karlstad, Sweden \\ ${ }^{e}$ Wihuri Research Institute, Haartmaninkatu 8, FI-00290 Helsinki, Finland \\ ${ }^{f}$ National Institute for Health and Welfare, Genomics and Biomarkers Unit, Biomedicum, FI-00290 \\ Helsinki, Finland
}

\begin{abstract}
Two complementary instrumental techniques were used, and the data generated was processed with advanced numerical tools to investigate the interactions between anti-human apoB-100 monoclonal antibody (anti-apoB-100 Mab) and apoB-100 containing lipoproteins. Partial Filling Affinity Capillary Electrophoresis (PF-ACE) combined with Adsorption Energy Distribution (AED) calculations provided information on the heterogeneity of the interactions without any a priori model assumptions. The AED calculations evidenced a homogenous binding site distribution for the interactions. Quartz Crystal Microbalance (QCM) studies were used to evaluate thermodynamics and kinetics of the Low-Density Lipoprotein (LDL) and antiapoB-100 Mab interactions. High affinity and selectivity were observed, and the emerging data sets were analysed with so called Interaction Maps. In thermodynamic studies, the interaction between LDL and anti-apoB-100 Mab was found to be predominantly enthalpy driven. Both techniques were also used to study antibody interactions with Intermediate-Density (IDL) and
\end{abstract}


Very Low-Density (VLDL) Lipoproteins. By screening affinity constants for IDL-VLDL sample in a single injection we were able to distinguish affinity constants for both subpopulations using the numerical Interaction Map tool.

Keywords: monoclonal anti-apoB-100 antibody; lipoproteins; thermodynamics; kinetics; interaction map

\section{Graphical abstract}

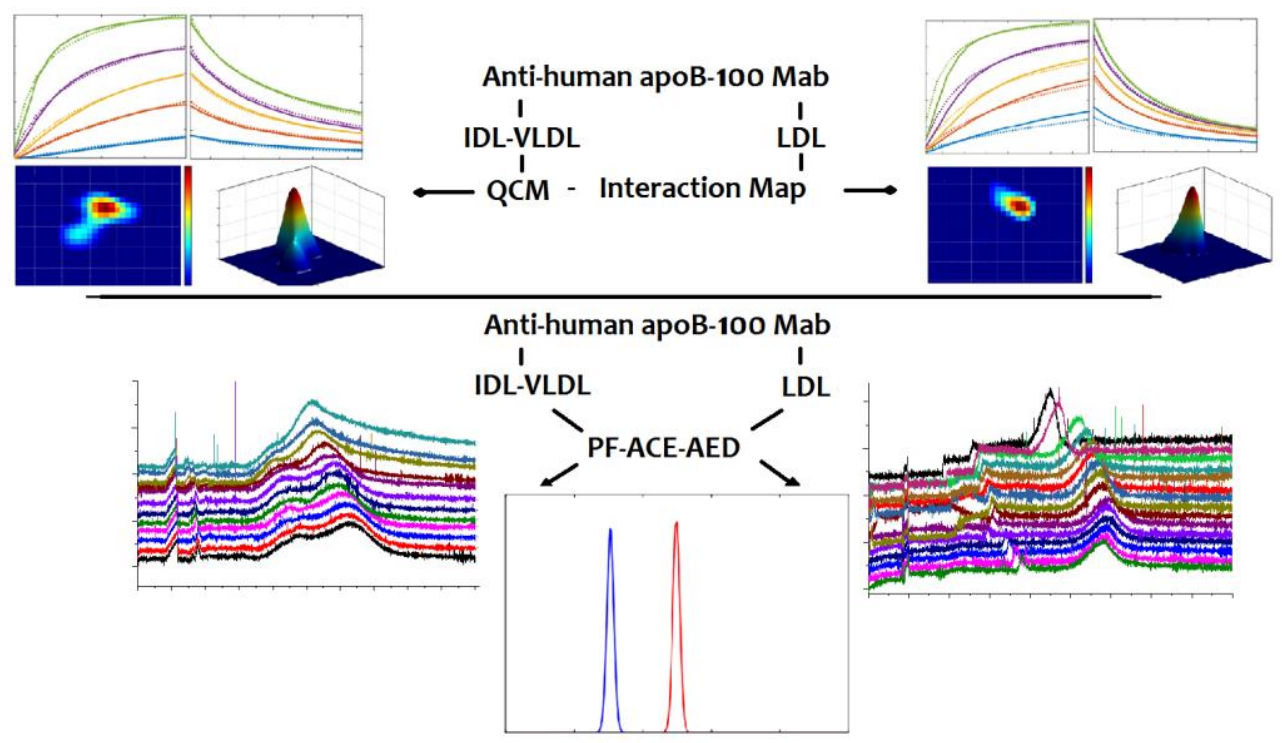

\section{Introduction}

Variety of techniques are available for evaluation of affinity constant $\left(K_{\mathrm{A}}\right)$, but they usually require either chemical modifications of the reactants, or indirect measurements. These techniques include affinity chromatography, radioimmunoassay, enzyme-linked immunosorbent assay, X-ray diffraction, nuclear magnetic resonance, mass spectroscopy, fluorescence-based methods, and isothermal titration calorimetry. Modern biosensor techniques like Quartz Crystal Microbalance (QCM) and surface plasmon resonance, as well as Partial Filling Affinity Capillary Electrophoresis (PF-ACE), allow the determination of affinity constants without any reactant modifications. 
QCM can measure association and dissociation rate of the molecules, and can be thus utilized to study kinetics and thermodynamics at different temperatures. PF-ACE on the other hand, with the combination of Adsorption Energy Distribution (AED) calculations, has proven to work as a sole method for the investigation of demanding biomolecular interactions [1]. In PFACE the reagents are flowing freely in a solution, as compared to QCM, where immobilization of one of the reagents is needed. PF-ACE/AED can be successfully used for elucidation of the heterogeneity of interactions, and determination of affinity constant [1-4].

When biosensors are used for affinity studies, it is relatively easy to generate data, while correct data interpretation may be problematic [5]. With poor experimental design and data interpretation, it is not unusual that biosensor data does not agree with the results achieved with other techniques [5]. To be able to use a simple binding isotherm with 1:1 interaction model, the response of the QCM should reach the plateau, in other words reach equilibrium, before the end of the analyte injection, which is called equilibrium analysis. In that case, affinity constants obtained with simple 1:1 kinetic model agree with equilibrium analysis, although in case of IgG molecule the 1:2 equilibrium is more typical. When all responses of the analyte injection reach the equilibrium, the equilibrium analysis can be used, in other cases it is not applicable [5]. However, for some biological systems more complex fitting models are required, combined with better ways to present the data.

Low Density Lipoproteins (LDL), Intermediate Density Lipoproteins (IDL) and Very LowDensity Lipoproteins (VLDL) are the major carriers of triglycerides and cholesterol in human circulation [6]. They consist mainly of hydrophobic core containing cholesteryl esters, triglycerides, fatty acids and fat-soluble vitamins, and the hydrophilic surface of apolipoproteins, phospholipids and un-esterified cholesterol [7]. ApoB-100 is the major apolipoprotein in LDL, IDL and VLDL, as well as in Lp(a), a specific LDL- and apo(a)containing complex. Main function of apoB-100 is to control the structural integrity of these 
lipoproteins, as well as to control their receptor-mediated removal from the circulation and other cellular interactions. The size of LDL particle is approximately $22 \mathrm{~nm}$ and can vary between 80-200 nm for VLDL particles [7]. Due to their complex nature, the lipoproteins have different sizes, masses and compositions and these metrics vary from one individual to other. Ultracentrifugation separates the lipoprotein species based on their hydrated density differences in a heterogeneous mass and size mixture. This affects especially the QCM experiments, since kinetics of association and dissociation for LDL particles with smaller particle diameter is different compared to that at the larger end of the size distribution. Complex fitting models are thus required, and the interactions can be presented as sensograms with model fits or even as an Interaction Map, which shows the distribution of association and dissociation constants.

In this study, mouse anti-human apoB-100 monoclonal antibody (anti-apoB-100 Mab) was used to study the interactions between lipoproteins containing apoB-100. PF-ACE/AED was exploited as a reference technique to QCM with Interaction Maps. PF-ACE/AED provided the information on the heterogeneity of the interaction, and QCM was used to investigate the kinetics and thermodynamics at different temperatures. Both techniques were employed to determine the affinity constants and they were evaluated in term of applicability for kinetic and thermodynamic information. The specificity of anti-human apoB-100 monoclonal antibody towards apoB-100 was evaluated by PF-ACE and its interaction with $\mathrm{HDL}_{2}$ including no apoB100.

\section{Material and methods}

\section{Chemicals and materials}

TWEEN 20, 4-(2-hydroxyethyl)-1-piperazineethanesulfonic acid) (HEPES), ethanolamine, and hydrochloric acid (fuming 37\%) were purchased from Sigma-Aldrich (St.Louis, MO, USA). Phosphoric acid was obtained from Merck (Darmstadt, Germany). Ammonia (25\%) was 
purchased from Riedel-de Haën (Seelze, Germany). NaCl was from Fisher Chemicals (Loughborough, UK). Dimethyl sulfoxide (DMSO), hydrochloric acid (0.1 - $1.0 \mathrm{M}$ ), and sodium hydroxide $(0.1-1.0 \mathrm{M})$ were obtained from Oy FFChemicals (Yli Ii, Finland). Ethylenediaminetetraacetic acid disodium salt dihydrate ( $\left.\mathrm{Na}_{2} \mathrm{EDTA}\right)$, bovine serum albumin (BSA), sodium citrate trihydrate $\left.\mathrm{C}_{6} \mathrm{H}_{5} \mathrm{O}_{7} .3 \mathrm{Na} 3 \mathrm{H}_{2} \mathrm{O}\right)$, and sodium azide $\left(\mathrm{NaN}_{3}\right)$ were from Sigma Chemicals Co. (St. Louis, MO, USA). Gentamycin sulfate (BioReagent, suitable for cell culture) was from Lonza (Basel, Switzerland). Sulfo-N-hydroxy-succinimide (S-NHS, 98.0\%) and 1-ethyl-3-(3-dimethylaminopropyl) carbodiimide hydrochloride (EDC-HCl, 98.5\%) were purchased from Aladin Chemical Regent Company (Shanghai, China). P2VP- $b$-PEO ( $M_{\mathrm{n}, \mathrm{P} 2 \mathrm{VP}}$ $\left.=3000 \mathrm{~g} / \mathrm{mol}, M_{\mathrm{n}, \text { PEO }}=10000 \mathrm{~g} / \mathrm{mol}, M_{\mathrm{w}} / M_{\mathrm{n}}=1.13\right)$ was purchased from Polymer Source (Dorval) (Montreal, QC, Canada). Human blood plasma was obtained from healthy volunteers (Finnish Red Cross Blood Service, Helsinki, Finland). LDL, IDL-VLDL and HDL2 were provided by Wihuri Institute (Helsinki, Finland). The monoclonal antibody $(5.3 \mathrm{mg} / \mathrm{ml}$ anti apoB-100 code Anti-h ApoB 2101 SPTN-5) was donated by Medix Biochemica Co. Inc (Helsinki, Finland). Distilled water was deionized using a Millipore water purification system (Millipore, Molsheim, France).

\section{Instrumentation}

The Attana A100 Quartz Crystal Microbalance (QCM) instrument (Attana AB, Stockholm, Sweden) was used for label-free analyses of molecular interactions. LNB-Carboxyl sensor chips (Attana $A B)$ providing low non-specific binding were used as the assay surface $[2,3,8$, 9]. Chamber and sample volumes were $1.25 \mu \mathrm{L}$ and $35 \mu \mathrm{L}$, respectively. The solvent flow rate used was $50 \mu \mathrm{l} / \mathrm{min}$. Temperatures in the kinetic studies were $25-40^{\circ} \mathrm{C}$. Attester software was used to monitor and record the resonant frequency of the quartz crystal and the frequency shift $(\Delta f)$ of association or dissociation. 
An Agilent ${ }^{3 \mathrm{D}} \mathrm{CE}$ instrument controlled through an Agilent $\mathrm{CE}$ ChemStation (Agilent, Waldbronn, Germany) was used for the PF-ACE experiments. The instrument was equipped with a diode array detector and a temperature controlling unit regulated by air during the analyses. Detection was done with UV at the $200 \mathrm{~nm}$ wavelength. Temperature of the electrolyte and sample vial unit in the CE was controlled by water perfusion from an external water bath (MGW Lauda K2, Lauda-Köningshofen, Germany). Temperature in the separation and the vial units was $37^{\circ} \mathrm{C}$.

Fused-silica capillaries (i.d. $50 \mu \mathrm{m}$ ) used in the study were purchased from Optronis GmbH, Kehl, Germany. In all the experiments, their efficient ( $\left.L_{\text {eff }}\right)$ and the total lengths $\left(L_{\text {tot }}\right)$ were 30.0 cm and $38.5 \mathrm{~cm}$, respectively. A WTW pH 7110 pH meter (WTW GmbH, Weilheim, Germany) was used to control the $\mathrm{pH}$ of the electrolyte solutions (BGE). The combination electrode were calibrated with buffer solutions (Fisher Scientific, UK) of pH 4 (phthalate, $\mathrm{pH} 3.98$ at $20^{\circ} \mathrm{C}$ ), pH 7 (phosphate, $\mathrm{pH} 7.02$ at $20^{\circ} \mathrm{C}$ ), and $\mathrm{pH} 10$ (borate, $\mathrm{pH} 9.99$ at $20^{\circ} \mathrm{C}$ ).

Ultracentrifugation was made using Beckman Optima TL Table-Top ultracentrifuge (Beckman Coulter, Brea, CA).

\section{Preparation of buffers and solutions}

Phosphate buffer $(I=20 \mathrm{mM})$ used in CE and QCM experiments was prepared by adding 485 $\mu \mathrm{l}$ of phosphoric acid (85\%) and dissolving it with $14.16 \mathrm{ml}$ of $1.0 \mathrm{M} \mathrm{NaOH}$ to $900 \mathrm{ml}$ of MilliQ water. The $\mathrm{pH}$ of the solution was first adjusted to 7.4 with $1.0 \mathrm{M} \mathrm{HCl}$ and then filled to the final volume of $1000 \mathrm{ml}$ with Milli-Q water. To calculate the ionic strength of the buffer, $\mathrm{p} K_{\mathrm{a}, 2}$ of 7.2 [10] was used for phosphoric acid.

In isolation of the biological compounds with dialysis studies the solution was phosphatebuffered saline (PBS, $\mathrm{pH}$ 7.4). It was prepared following the standard procedure. $1 \mathrm{M}$ ethanolamine solution ( $\mathrm{pH}$ 9.0) was prepared by adjusting the $\mathrm{pH}$ with hydrochloric acid 
(fuming 37\%). Preparation of $0.28 \mathrm{M}$ ammonium hydroxide (pH 11.5) was done by dissolving $1.13 \mathrm{ml}$ of $25 \%$ ammonia into the $50 \mathrm{ml}$ of Milli-Q water.

Phosphate buffer $(I=20 \mathrm{mM})$ was used to dilute anti-apoB-100 Mab $(100 \mu \mathrm{g} / \mathrm{ml})$ for using the antibody in amine coupling on the LNB-Carboxyl layer on the biosensor chips. The buffer (10 mM HEPES, $150 \mathrm{mM} \mathrm{NaCl}, 0.005 \%$ Tween 20, pH 7.4) for the immobilization was prepared by dissolving $1.19 \mathrm{~g}$ of HEPES with $4.38 \mathrm{~g}$ of NaCl and $0.25 \mathrm{ml}$ of $10 \%$ Tween 20 in $400 \mathrm{ml}$ of Milli-Q water, followed by adjustment to $\mathrm{pH} 7.4$ with $1.0 \mathrm{M} \mathrm{NaOH}$. Final volume of the immobilization buffer was adjusted to $500 \mathrm{ml}$ with MilliQ water. Activation reagents, $0.4 \mathrm{M}$ EDC and 0.1 M S-NHS, were both dissolved in Milli-Q water before mixing. LDL and IDLVLDL samples (3-110 $\mu \mathrm{g} / \mathrm{ml})$ used in QCM experiments were diluted in the phosphate buffer $(I=20 \mathrm{mM})$. Regeneration solution for QCM experiments was prepared by diluting $25 \%$ ammonia in MilliQ water to obtain $0.28 \mathrm{M}$ ammonium hydroxide $\mathrm{pH}$ 11.5. All stock solutions were stored at $+4^{\circ} \mathrm{C}$ and $-20^{\circ} \mathrm{C}$.

\section{Production of monoclonal antibody}

Monoclonal antibody was produced in vitro using mouse hybridoma production technology. Splenocytes were collected from the immunized mouse and the highest antisera titer were fused with myeloma cells [11]. Mice were immunized with highly purified human LDL. In vitro cultured hybridoma cells secreted specific anti-human apoB-100 monoclonal antibody (IgG1 class) in culture medium. The antibody was purified by protein affinity chromatography. Clear solution of purified IgG1 subclass was made in $50 \mathrm{mM}$ Na-citrate, $\mathrm{pH} 6.0,0.9 \% \mathrm{NaCl}$ containing $0.095 \% \mathrm{NaN}_{3}$ as anti-bacterial agent and stored at $+4^{\circ} \mathrm{C}$. Before use the solution was dialyzed against phosphate-buffered saline (PBS, pH 7.4). Epitope in apoB-100 polypeptide chain recognized by this established anti-apoB-100 Mab is not known.

\section{Isolation and characterization of Low Density Lipoprotein (LDL)}

Human LDL $(d=1.019-1.050 \mathrm{~g} / \mathrm{ml})$ was isolated by sequential ultracentrifugation in the 
presence of $3 \mathrm{mmol} / 1 \mathrm{Na}_{2}$ EDTA $[12,13]$. First, EDTA and $100 \mu \mathrm{g} / \mathrm{ml}$ gentamycin sulfate were added to the plasma sample and the density was adjusted to 1.019 with $\mathrm{KBr}$. Then, the plasma sample was centrifuged at $40000 \mathrm{rpm}$ (rotor $50.2 \mathrm{Ti}$, gmax 302000 ) at $+4^{\circ} \mathrm{C}$ for $24 \mathrm{~h}$. The IDLVLDL fraction was collected from the top and the density of the remaining plasma was set to $1.050 \mathrm{~g} / \mathrm{ml}$ with $\mathrm{KBr}$. The density-adjusted plasma was centrifuged at $40000 \mathrm{rpm}$ for $72 \mathrm{~h}$ and the plasma for further steps was collected on the top of the solution. The collected solution was re-centrifuged at a density of $1.063 \mathrm{~g} / \mathrm{ml}$ for $24 \mathrm{~h}$, collected and dialyzed extensively against $150 \mathrm{mM} \mathrm{NaCl}$ - 1 mM EDTA (pH 7.4) followed by dialysis against phosphate-buffered saline (PBS, pH 7.4) which was used for CE analyses. The amounts of LDL and VLDL-IDL are expressed in terms of the protein concentration. The concentrations including that of anti-apoB$100 \mathrm{Mab}$ were determined by the method of Lowry et al. [14] or by BCA protein assay kit (Pierce, Rockford, IL) using bovine serum albumin as the standard. Molar concentrations of LDL, IDL-VLDL were calculated using molecular weight of apoB-100 (512 kDa). For antiapoB-100 Mab, molecular weight of $155 \mathrm{kDa}$ was used.

\section{Isolation of high-density lipoprotein $\left(\mathrm{HDL}_{2}\right)$}

$\mathrm{HDL}_{2}$ was isolated from serum and plasma samples by sequential ultracentrifugation and $\mathrm{KBr}$ was used for density adjustment. After the first isolation of apoB-containing lipoproteins at $d=$ $1.063 \mathrm{~g} / \mathrm{mL}\left(5^{\circ} \mathrm{C}, 3 \mathrm{~h}, 500,000 \mathrm{x} \mathrm{g}\right)$, the infranatant fraction was adjusted to density $1.125 \mathrm{~g} / \mathrm{mL}$ with solid $\mathrm{KBr}$ and then centrifuged $\left(5^{\circ} \mathrm{C}, 18 \mathrm{~h}, 500,000 \mathrm{x}\right.$ g). The $\mathrm{HDL}_{2}$ was obtained in top fraction. The purity of the isolated $\mathrm{HDL}_{2}$ was checked with FPLC size-exclusion chromatography. The isolated $\mathrm{HDL}_{2}$ was dialyzed against phosphate-buffered saline (PBS, $\mathrm{pH}$ 7.4) and stored at $-80^{\circ} \mathrm{C}$ before analysis.

\section{Sample preparation}

The solutions of anti-apoB-100 Mab (0.0002 - $0.1 \mathrm{mg} / \mathrm{ml})$ used as binding ligand in PF-ACE experiments were diluted in phosphate buffer $(I=20 \mathrm{mM})$. In addition, LDL $(0.075 \mathrm{mg} / \mathrm{ml})$, 
IDL-VLDL $(0.036 \mathrm{mg} / \mathrm{ml})$, and $\mathrm{HDL}_{2}(0.2 \mathrm{mg} / \mathrm{ml})$ used as the antigens in PF-ACE were diluted in phosphate buffer $(I=20 \mathrm{mM})$. DMSO $(1 \% \mathrm{v} / \mathrm{v})$ was dissolved in Milli-Q water. Immobilization solution was prepared in the same manner as mentioned above from phosphate, but $\mathrm{pH}$ was adjusted to 6.4 with $1.0 \mathrm{M} \mathrm{HCl}$.

\section{Immobilization of anti-apoB-100 Mab on LNB-Carboxyl sensor chip}

Immobilization of anti-apoB-100 Mab was done with amine coupling procedure according to manufacturer's recommendations with slight modifications. Prior to the immobilization the LNB-Carboxyl sensor chip was pre-wetted ex-situ with $20 \mu \mathrm{l}$ of Milli-Q water and thereafter inserted into the instrument and left to stabilize. The immobilization was performed with the analysis buffer (10 mM HEPES, $150 \mathrm{mM} \mathrm{NaCl}, 0.005 \%$ Tween $20, \mathrm{pH} 7.4)$ at the flow rate of $10 \mu \mathrm{l} / \mathrm{min}$ under $25^{\circ} \mathrm{C}$. To activate the surface, freshly mixed $0.4 \mathrm{M}$ EDC and $0.1 \mathrm{M}$ S-NHS $(1: 1, \mathrm{v} / \mathrm{v})$ was injected using automated C-Fast software for 5 minutes. The surface activation was done only once. The amine coupling of anti-apoB-100 Mab $(100 \mu \mathrm{g} / \mathrm{ml}$ in phosphate buffer; $\mathrm{pH}$ 6.4) was carried out by injecting the solution twice for 5 minutes. Finally, the remaining carboxyl groups were deactivated with two injections (5 minutes each) of $1 \mathrm{M}$ ethanolamine solution ( $\mathrm{pH}$ 9.0).

\section{QCM interaction studies at different temperatures}

LDL and IDL-VLDL experiments were all carried out at flow rate of $50 \mu 1 /$ min with injection volume of $35 \mu \mathrm{l}$. LDL and anti-apoB-100 Mab interactions were studied at temperatures of $25.0,34.0,35.0,36.0,37.0,38.0,39.0$, and $40.0^{\circ} \mathrm{C}$. IDL-VLDL and anti-apoB-100 Mab interactions were studied at $37.0^{\circ} \mathrm{C}$. LDL and IDL-VLDL concentrations ranged from 3 to 110 $\mu \mathrm{g} / \mathrm{ml}$. Three repetitions were made to verify the precision of the data. In this study, we assume that the Sauerbrey relation is valid and that the QCM frequency shifts are proportional to the adsorbed amount of solute [15]. 


\section{QCM analysis of anti-apoB-100 Mab - lipoprotein interactions}

The measurements started after the waiting period of 20 minutes to stabilize the resonant frequency. LDL and IDL-VLDL samples were injected to the surface of chips, monitoring first the association for 50 seconds and then the dissociation for 500 seconds. After each association and dissociation cycle, the biosensor chip was regenerated with injection of $0.28 \mathrm{M}$ ammonium hydroxide ( $\mathrm{pH} 11.5)$ and re-equilibrated with the analysis buffer.

\section{Estimation of kinetic rate constants}

Estimation of kinetic rate constants is an inverse problem, i.e., a problem where given the response of the system we want to estimate system parameters. Here we are going to estimate system parameter distributions rather than a finite set of system parameters values.

In general, assuming that the total measured response, $R_{\mathrm{tot}}$, of a system can be written as a linear combination of some individual responses $r$ (e.g. $R_{\mathrm{tot}}$ is the sum of the responses for all one-toone interactions for biosensors) we have that,

$$
R_{\mathrm{tot}}(\mathbf{x})=\sum_{i=1}^{n} a_{i} \cdot R\left(\mathbf{p}_{i} ; \mathbf{x}\right)
$$

where $\mathbf{x}$ is the independent variable(s) for the system, e.g. the analysis time, $\mathbf{p}$ is the system parameter(s), e.g. rate constants, and $a$ is a constant. If we let $n$ in Eq. (1) $\rightarrow \infty$ we get that,

$$
R_{\mathrm{tot}}(\mathbf{x})=\int_{\Omega} a(\mathbf{p}) \cdot R(\mathbf{p} ; \mathbf{x}) d^{m} \mathbf{p}
$$

where $\Omega \subseteq \Upsilon^{\mathrm{m}}$ is the considered system parameter space. Eq. (2) is known as an Inhomogeneous Fredholm Integral Equation of the first kind with kernel $R$ and our goal is to estimate the function $a(\mathbf{p})$. Assume that we have measured the total response $R_{\mathrm{tot}}(\mathbf{x})$ for the system, and discretize Eq. (2), the problem of estimating $a(\mathbf{p})$ can be written as a linear system of the form,

$$
\mathbf{M}(\mathbf{p}, \mathbf{x}) \cdot \mathbf{a}(\mathbf{p})=\mathbf{R}_{\text {tot }}(\mathbf{x})
$$


where $\mathbf{M}$ is a matrix and $\mathbf{a}, \mathbf{R}_{\mathrm{tot}}$ are discrete sample vectors of $a(\mathbf{p})$ and $R_{\mathrm{tot}}(\mathbf{x})$, respectively. Eq. (3) is usually an ill-conditioned over- or underdetermined linear system and often the condition $\mathbf{a} \geq \mathbf{0}$ is imposed. In order to get reasonable solutions to Eq. (3) regularization is often used, the most common one is Tikhonov regularization where we instead of Eq. (3) solve the following linear system,

$$
\left(\mathbf{M}^{T} \mathbf{M}+\lambda^{2} \boldsymbol{\Gamma}^{2} \boldsymbol{\Gamma}\right) \mathbf{a}=\mathbf{M}^{T} \mathbf{r}_{\text {tot }}
$$

where $\Gamma$ is a regularization matrix (usually an identity or Laplacian matrix) and $\lambda$ is a regularization parameter.

For biosensors the kernel $R$ in Eq. (2) can be written,

$$
R\left(t, C ; k_{\mathrm{a}}, k_{\mathrm{d}}\right)= \begin{cases}0 & , t \leq t_{0}, \\ \frac{k_{\mathrm{a}} C}{k_{\mathrm{a}} C+k_{\mathrm{d}}}\left(1-\exp \left(-\left(k_{\mathrm{a}} C+k_{\mathrm{d}}\right)\left(t-t_{0}\right)\right)\right) & , t_{0}<t \leq t_{0}+t_{\mathrm{inj}}, \\ \frac{k_{\mathrm{a}} C}{k_{\mathrm{a}} C+k_{\mathrm{d}}}\left(1-\exp \left(-\left(k_{\mathrm{a}} C+k_{\mathrm{d}}\right) t_{\mathrm{inj}}\right)\right) \cdot \exp \left(-k_{\mathrm{d}}\left(t-t_{0}-t_{\mathrm{inj}}\right)\right) & , t>t_{0}+t_{\mathrm{inj}},\end{cases}
$$

where $t$ (analysis time) and $C$ (analyte concentration) are the independent variables and $k_{\mathrm{a}}$, (association rate constant) and $k_{\mathrm{d}}$ (disassociation rate constant) are non-negative system parameters. Above $t_{0}$ is the time when the injection of the analyte begins and $t_{\text {inj }}$ is the injection time. The solution $a\left(k_{\mathrm{a}}, k_{\mathrm{d}}\right)$ to Eq. (2) with the kernel in Eq. (5) is known as an Interaction Map $[16,17]$, see Figs. 3 and 5. The Interaction Maps in this study were calculated using the TraceDrawer software from Ridgeview Instruments AB, Sweden.

\section{Capillary electrophoresis coating procedure}

Unfavorable adsorption of lipoproteins on the negatively charged fused-silica capillary was diminished by coating the capillary inner wall with quaternized double-hydrophilic poly $(N$ methyl-2-vinyl pyridinium iodide-block-ethylene oxide) (P2QVP-b-PEO) diblock copolymer [18]. P2QVP-b-PEO $(0.1 \mathrm{mg} / \mathrm{ml})$ was dissolved in Milli-Q water. Coating procedure was slightly modified from previous studies [1, 18]. First an uncoated fused-silica capillary was 
pretreated by flushing for $15 \mathrm{~min}, 10 \mathrm{~min}$, and $10 \mathrm{~min}$ with $0.1 \mathrm{M} \mathrm{NaOH}$, Milli-Q water, and phosphate buffer $(\mathrm{pH} 7.4, I=20 \mathrm{mM})$ at the pressure of 940 mbar. Then the capillary was flushed for $20 \mathrm{~min}, 10 \mathrm{~min}, 25 \mathrm{~min}$, and $5 \mathrm{~min}$ with $1 \mathrm{M} \mathrm{HCl}, 0.1 \mathrm{M} \mathrm{HCl}$, Milli-Q water, and the $\mathrm{pH} 7.4$ phosphate buffer, respectively, at the pressure of 940 mbar. After pretreatment, the voltage of $+15 \mathrm{kV}$ was applied for $5 \mathrm{~min}$. The P2QVP- $b$-PEO coating solution was then applied for $40 \mathrm{~min}$ and left for $30 \mathrm{~min}$ to react with the silanol groups on the capillary surface. Excess copolymer solution in phosphate buffer was then rinsed by flushing through the capillary for $60 \mathrm{~min}$ at the pressure of 940 mbar. The coating procedure with the polymer solution was repeated twice to ensure the best possible stability of the wall coating. The whole procedure was conducted at $37.0^{\circ} \mathrm{C}$. To ensure the success of the coating, electro-osmotic flow (EOF) mobility was measured using DMSO with the Williams and Vigh method [19]. The stability of the mobility value was controlled also during the kinetic studies. It was to be at the level of $10^{-}$ ${ }^{9}-10^{-10} \mathrm{~m}^{2} \mathrm{~V}^{-1} \mathrm{~s}^{-1}$

\section{Partial filling procedure}

Partial filling (PF) procedure in CE was slightly modified from our previous studies [1-4, 20]. Briefly, negatively charged analytes were hydrodynamically introduced to the coated capillary. First, slightly negative anti-apoB-100 Mab was introduced in the concentration range of 0.0002 to $0.1 \mathrm{mg} / \mathrm{ml}$ for $3 \mathrm{~s}$, followed by injection of the more negative lipoproteins at $50 \mathrm{mbar}$ pressure [18]. The lipoprotein concentrations were different in the antibody-antigen reactions. LDL $(0.075 \mathrm{mg} / \mathrm{ml})$ was introduced for $2 \mathrm{~s}$, IDL-VLDL $(0.0036 \mathrm{mg} / \mathrm{ml})$ for $8 \mathrm{~s}$, and $\mathrm{HDL}_{2}(0.20$ $\mathrm{mg} / \mathrm{ml}$ ) for $2 \mathrm{~s}$ at 50 mbar. When the voltage of $-25 \mathrm{kV}$ was applied and detector was in the cathode end, more anionic lipoproteins reached anti-apoB-100 Mab and formed the LDL - antiapoB-100 Mab complex and the IDL-anti-apoB-100 Mab and the VLDL - anti-apoB-100 Mab complexes. $\mathrm{HDL}_{2}$ lacking apoB-100 was used as a control to test the specificity of the antiapoB-100 Mab. The detection was performed at the wavelength $200 \mathrm{~nm}$. Before each run, the 
capillary was rinsed for 2 min with the phosphate buffer (pH 7.4). All the experiments were conducted at $37.0^{\circ} \mathrm{C}$. After every second run, the EOF mobility was measured to control the stability of the coating.

\section{Determination of affinity constants with PF-ACE}

To determine the affinity constants for complexes between LDL, ILD-VLDL and anti-apoB$100 \mathrm{Mab}$, the AED calculations were used. First, the LDL or IDL-VLDL fractions, bound to anti-apoB-100 Mab, were established as a function of anti-apoB-100 Mab concentrations. The interactions were studied by injecting anti-apoB-100 Mab with increasing concentrations, followed by a constant LDL or IDL-VLDL concentration and volume. Then the voltage was applied and LDL or IDL-VLDL having more charges than anti-apoB-100 Mab reached the antiapoB-100 Mab and interacted with it. The average mobility of the antibody-antigen complex can be described with following equation [21]:

$$
\mu^{\mathrm{A}}=\Theta_{\mathrm{f}} \mu_{\mathrm{f}}+\Theta_{\mathrm{b}} \mu_{\mathrm{b}}
$$

where $\Theta_{\mathrm{f}}$ and $\Theta_{\mathrm{b}}$ are the free and bound fractions of LDL or IDL-VLDL, respectively, and $\mu_{\mathrm{f}}$ and $\mu_{\mathrm{b}}$ are the mobilities of free and bound LDL or IDL-VLDL to anti-apoB-100 Mab, and $\mu^{\mathrm{A}}$ is the average mobility of the complex. Since $\Theta_{\mathrm{f}}+\Theta_{\mathrm{b}}=1$, equation of adsorbed fraction can be presented as:

$$
\Theta_{\mathrm{b}}=\frac{\mu^{\mathrm{A}}-\mu_{\mathrm{f}}}{\mu_{\mathrm{b}}-\mu_{\mathrm{f}}}
$$

The mobilities of the adsorbed and free fractions were investigated with exponential and linear fitting, respectively. At the lower end of the concentration range, electrophoretic mobility decreased linearly towards the minimum value, where LDL or IDL-VLDL was in free form. At the high concentration end, where LDL or IDL-VLDL was completely bound to anti-apoB-100 Mab, electrophoretic mobility reached the maximum value. 


\section{Adsorption isotherms and adsorption energy distribution}

Adsorption isotherms describe the fraction of analyte adsorbed or in free solution at equilibrium to a constant and specific temperature $[22,23]$. Langmuir model describes adsorption to a limited number of equal adsorption sites can be expressed as:

$$
\theta=\frac{K_{\mathrm{A}} C}{1+K_{\mathrm{A}} C}
$$

where $C$ is the analyte concertation in the running buffer, $\theta$ is fractional surface coverage and $K_{\mathrm{A}}$ is the association equilibrium constant. As described above the Langmuir model can only describe one type of interaction. However, many adsorption processes are a result of several different type of interactions such as ion-ion, hydrophobic interactions etc. One simple way to model heterogeneous adsorption process is to use the bi-Langmuir adsorption isotherm. The BiLangmuir model is just the sum of two Langmuir models, and can be presented as:

$$
\theta=\theta_{\mathrm{S}, 1} \frac{K_{\mathrm{A}, 1} C}{1+K_{\mathrm{A}, 1} C}+\theta_{\mathrm{S}, 2} \frac{K_{\mathrm{A}, 2} C}{1+K_{\mathrm{A}, 2} C}
$$

Here, indices 1 and 2 denote the first and second adsorption sites, respectively. $\theta_{\mathrm{S}, i}$ is the saturation fraction for the $i$ :th site. Observe that $\theta_{\mathrm{S}, 1}+\theta_{\mathrm{S}, 2}=1$. One other way to describe heterogeneous adsorption is to expanding the Langmuir adsorption isotherm model into a continuous distribution of independent homogeneous sites across a certain range of adsorption energies as done below [3, 24]:

$$
\left\{\begin{array}{l}
\theta(C)=\int_{K_{\mathrm{A}, \min }}^{K_{\mathrm{A}, \max }} f\left(\ln K_{\mathrm{A}}\right) \theta\left(C, K_{\mathrm{A}}\right) d \ln K_{\mathrm{A}} \\
\theta\left(C, K_{\mathrm{A}}\right)=\frac{K_{\mathrm{A}} C}{1+K_{\mathrm{A}} C}
\end{array}\right.
$$

Here, $\theta\left(C, K_{\mathrm{A}}\right)$ is the local adsorption model, and $f\left(\ln K_{\mathrm{A}}\right)$ is the adsorption energy distribution (AED). $K_{\mathrm{A}, \min }$ and $K_{\mathrm{A}, \max }$ are determined from the inverse maximum and minimum sample 
concentration used in the CE experiments. In this study, the AED is solved using the expectation maximization method, where the integral equation is iteratively solved [25]. Observe that both the AED in Eq. (10) and Interaction Maps are Inhomogeneous Fredholm Integral Equations of the first kind with kernel $\theta\left(C, K_{\mathrm{A}}\right)$, see Eq. (2).

\section{Results and discussion}

Interactions between anti-apoB-100 Mab and lipoprotein were studied with PF-ACE/AED and QCM with Interaction Map. In PF-ACE studies, anti-apoB-100 Mab was freely floating in background electrolyte solution under physiological buffer conditions so in that sense the system resembles conditions in general blood circulation. However, in the QCM studies were carried out under the same conditions where anti-apoB-100 Mab was immobilized covalently onto the chip surface. Due to its high reliability, the QCM system allowed to study the kinetics and the thermodynamics of the antibody-antigen interactions.

\section{Partial filling affinity capillary electrophoresis}

Adsorption isotherms for the interactions between LDL, IDL-VLDL and anti-apoB-100 Mab were determined at $37^{\circ} \mathrm{C}$ by PF-ACE. To avoid non-specific adsorption of lipoproteins onto the negatively charged fused silica capillary surface, the capillary inner wall was coated with P2QVP-b-PEO diblock copolymer [18]. The coating was freshly prepared for each interaction study. EOF mobilities of every second run were monitored using Williams and Vigh method [19] to correct the migration times of the analytes. Since lipoproteins have higher mobilities due to their negative charges than the anti-apoB-100 Mab that is almost immobile at pH 7.4 (pI 7.0), they were hydrodynamically introduced into the capillary after anti-apoB-100 Mab, and they reached anti-apoB-100 Mab in the capillary resulting in quick antibody-antigen immunocomplex formation. As expected no complex was formed between anti-apoB-100 Mab and $\mathrm{HDL}_{2}$ lacking apoB-100. This confirmed the specific nature of anti-apoB-100 Mab towards apoB-100 containing lipoproteins, leading to migration time changes of apoB-100 Mab 
complexes with LDL and IDL-VLDL (Fig.1). We also observed that system peaks in the beginning of the electropherograms were caused by anionic ions caused by bromide ion of $\mathrm{KBr}$ that was used to adjust density of the lipoproteins in the ultracentrifugation. This was eliminated by replacing the ultracentrifugation medium with PBS solution resulting in bromide free broad IDL-VLDL peak (Fig. 1 B). Electropherograms of Fig. 1 provided the raw adsorption isotherm data for LDL and IDL-VLDL, see Eq. (7). The affinity constants were calculated from Scatchard plot analysis and heterogeneity of the adsorption isotherm models were analyzed with AED calculations using the median values of the adsorption data for LDL, IDL-VLDL and anti-apoB-100 Mab systems at $37^{\circ} \mathrm{C}$. Fig. 2 demonstrates a single site model adsorption. Table 1 shows the affinity constant for LDL and anti-apoB-100 Mab interaction obtained by PFACE/AED, while Table 3 lists the affinity constants for IDL-VLDL and anti-apoB-100 Mab interaction. A slightly higher affinity constant $\left(K_{\mathrm{A}}=(4.94 \pm 1.33) \cdot 10^{7} \mathrm{M}^{-1}, \log K_{A}=7.69\right)$ was measured for interaction between IDL-VLDL and anti-apoB-100 Mab compared to that between LDL and anti-apoB-100 $\mathrm{Mab}\left(K_{\mathrm{A}}=(2.54 \pm 0.88) \cdot 10^{7} \mathrm{M}^{-1}, \log K_{A}=7.41\right)$.

\section{Effect of temperature on affinity and kinetics studied by QCM}

To study the effect of temperature on the affinity and kinetics of the interactions between LDL and anti-apoB-100 Mab by QCM, the following temperatures were used 25.0, 34.0, 35.0, 36.0, $37.0,38.0,39.0$, and $40.0^{\circ} \mathrm{C}$. The data points were determined three times at specified temperature. Fig. 3 shows selected sensorgrams, along with model fits for association and dissociation, as well as Interaction Maps at $37^{\circ} \mathrm{C}$. The response and representative QCM sensograms at all the concentrations employed for LDL can be found in Figs. S1 and S2. The kinetics and affinity parameters at $37^{\circ} \mathrm{C}$ were estimated from the Interaction Map peak using Ridgeview software and thereby kinetic parameters, such as association rate constant $\left(8.61 \cdot 10^{5}\right.$ $\left.\mathrm{M}^{-1} \mathrm{~s}^{-1}\right)$ and dissociation rate constant $\left(9.55 \cdot 10^{-3} \mathrm{~s}^{-1}\right)$ were obtained. Affinity constant $\left(K_{\mathrm{A}}=\right.$ $\left.9.02 \cdot 10^{7} \mathrm{M}^{-1}, \log K_{A}=7.96\right)$ for LDL and anti-apoB-100 Mab was calculated from the ratio of 
binding rate constants $K_{A}=1 /\left(k_{\mathrm{d}} / k_{\mathrm{a}}\right)$. The kinetics and affinity parameters for LDL and antiapoB-100 Mab interactions at other temperatures were evaluated following the same procedure. From the data in Table 1 measured from the QCM experiments it can be seen that while the association rate constant stayed relatively unchanged when going from 25 to $40^{\circ} \mathrm{C}$, the dissociation rate constant increased 10 -fold, resulting also in 10-fold loss in affinity from $4.68 \cdot 10^{8}$ to $4.57 \cdot 10^{7} \mathrm{M}^{-1}\left(\log K_{A}=8.67\right.$ to $\left.\log K_{A}=7.66\right)$.

\section{Thermodynamic studies carried out by quartz crystalline microbalance}

In this study, the QCM sensor was used to provide thermodynamic parameters, which can be used to elucidate if LDL and anti-apoB-100 Mab interaction is enthalpy or entropy driven. Data received from Interaction Maps (Table 1) were used. When enthalpy change is not temperature dependent van't Hoff plot $(\ln K$ vs $1 / T)$ results in a linear slope $-\Delta H / R$ [26], and thermodynamic parameters can be obtained from the following equation:

$$
\ln K=\frac{-\Delta H}{R T}+\frac{\Delta S}{R}
$$

where $K$ is association constant, $\Delta S$ is change in entropy, $\Delta H$ is enthalpy change, $T$ is temperature, and $R$ being the gas constant $8.314 \mathrm{JK}^{-1} \mathrm{~mol}^{-1}$.

Fig. 4 shows van't Hoff plot of $\ln K$ as a function of $1 / T$, which appears to be nearly linear, indicating that enthalpy change $(\Delta \mathrm{H})$ was temperature independent. The results (Table 2) calculated from the van't Hoff plot indicate that interaction between LDL and anti-apoB-100 Mab is predominantly enthalpy driven, resulting in the following thermodynamic parameters: $\Delta H=-116.7 \mathrm{~kJ} \mathrm{~mol}^{-1}$, and $\Delta S=-225.0 \mathrm{~J} \mathrm{~K}^{-1} \mathrm{~mol}^{-1}$.

\section{Study of IDL-VLDL and anti-apoB-100 Mab interactions}

QCM was also used to elucidate the interactions at physiological temperature $37^{\circ} \mathrm{C}$ between anti-apoB-100 Mab and IDL-VLDL that were co-isolated without separation by ultracentrifugation. Similarly to LDL studies, each of the data point was determined three times. 
Fig. 5 shows selected sensograms, along with model fits for association and dissociation, as well as Interaction Maps at $37^{\circ} \mathrm{C}$. The response and representative QCM sensograms at all the concentrations used for IDL-VLDL can be found in Figs. S3 and S4. The kinetics and affinity parameters at $37^{\circ} \mathrm{C}$ were estimated from the Interaction Map peak using TraceDrawer software. From the Interaction Map (Fig. 5) it is evident that the interactions between anti-apoB-100 Mab and IDL-VLDL produced two peaks that represented binding-like processes with distinct kinetic parameters. Association rate constant for site 1, which represents the highest peak with a weight of $64 \%$ was $5.54 \cdot 10^{5} \mathrm{M}^{-1} \mathrm{~s}^{-1}$, and it had a dissociation rate constant of $5.54 \cdot 10^{-3} 3 \mathrm{~s}^{-1}$. Affinity constant for site $1\left(K_{\mathrm{A}}=1.00 \cdot 10^{8} \mathrm{M}^{-1}, \log K_{A}=8.00\right)$ was calculated from the ratio of binding rate constants $K_{A}=1 /\left(k_{\mathrm{d}} / k_{\mathrm{a}}\right)$. Association rate constant for site 2 represents the smaller peak (Fig. 5) with a weight of $22 \%$ was $5.15 \cdot 10^{4} \mathrm{M}^{-1} \mathrm{~s}^{-1}$, and it had a dissociation rate constant of $8.07 \cdot 10^{-4} \mathrm{~s}^{-1}$. Affinity constant for site $2\left(K_{\mathrm{A}}=6.38 \cdot 10^{7} \mathrm{M}^{-1}, \log K_{A}=7.80\right)$ was also calculated from the ratio of binding rate constants $K_{A}=1 /\left(k_{\mathrm{d}} / k_{\mathrm{a}}\right)$. Results for IDL-VLDL and anti apoB-100 Mab interaction study are shown in Table 3.

QCM study of LDL, IDL-VLDL and anti-apoB-100 Mab interactions at $37^{\circ} \mathrm{C}$ gave slightly higher affinity for IDL-VLDL $\left(\log K_{A}=8.00\right.$, site 1$)$ than for LDL $\left(\log K_{A}=7.96\right)$, supported by PF-ACE/AED studies (Fig. 2, Tables 1 and 3). Site $2\left(\log K_{A}=7.80\right)$ had on the other hand lower affinity than LDL. The association rate constant $\left(5.54 \cdot 10^{5} \mathrm{M}^{-1} \mathrm{~s}^{-1}\right)$ for interaction site 1 for IDL-VLDL was slightly lower to that of $\operatorname{LDL}\left(8.61 \cdot 10^{5} \mathrm{M}^{-1} \mathrm{~s}^{-1}\right)$, and even lower for site 2 $\left(5.15 \cdot 10^{4} \mathrm{M}^{-1} \mathrm{~s}^{-1}\right)$, most probably due to higher mass of both IDL and VLDL compared to LDL. The dissociation rate constant for LDL was $9.55 \cdot 10^{-3} \mathrm{~s}^{-1}$, while for IDL-VLDL the constants were $5.54 \cdot 10^{-3} \mathrm{~s}^{-1}$ for site 1 , and $8.07 \cdot 10^{-4} \mathrm{~s}^{-1}$ for site 2 . The results prove that slower dissociation was again caused by larger mass of both IDL and VLDL compared to that of LDL. This was also noticed by Guha et al., who concluded that structural stability of LDL and VLDL is determined by kinetic barriers, resulting in decelerated interconversion among lipoprotein 
subclasses and classes [27]. IDL also forms a minor component in the isolated IDL-VLDL fraction, and due to the different masses and overall compositions, the IDL and VLDL interacted with anti-apoB-100 Mab with different kinetics resulting in two peaks in the Interaction Map (Fig. 5). Isolated LDL sample resulted on the other hand demonstrated only one peak in the Interaction Map (cf. Fig. 3).

\section{Conclusions}

Partial filling affinity capillary electrophoresis combined with adsorption energy distribution calculations and quartz crystal microbalance with Interaction Maps were successfully utilized to study kinetics and thermodynamics in the anti-apoB-100 Mab and apoB-100 containing lipoprotein complex formation. Thermodynamic studies demonstrated that LDL and anti-apoB$100 \mathrm{Mab}$ interaction was predominantly enthalpy-driven. Interaction Maps that visualize in an excellent way the association and dissociation phenomena, were used to study the kinetics of the LDL and anti-apoB-100 Mab antigen-antibody complex formation at different temperatures. It was found that while association rate constant was not affected much by changes in temperature, the dissociation rate constant increased 10 -folds from $25^{\circ} \mathrm{C}$ to $40^{\circ} \mathrm{C}$. Interaction between combined IDL-VLDL fraction and anti-apoB-100 Mab was also studied and Interaction Maps enabled to distinguish two distinct kinetic parameters for IDL-VLDL fraction in a single run. QCM combined with Interaction Map calculations has a great potential to study selectively biomolecular interactions of biological sample mixtures. PF-ACE with AED confirmed that the interaction between anti-apoB-100 Mab and apoB-100 containing lipoproteins was homogenous with a single site adsorption model. The affinity data obtained with QCM and PF-ACE agreed very well with each other, thus proving proof for their reliable use in biomolecular interaction studies. 


\section{AUTHOR INFORMATION}

\section{Corresponding Author}

*E-mail: marja-liisa.riekkola@helsinki.fi

Tel: $+358-40-5058848$

Notes: The authors declare no competing financial interest.

\section{Acknowledgements}

Financial support of the study was provided by the Jane and Aatos Erkko Foundation (E.M., H.S. and M.-L.R.) and the Research Council for Health, Academy of Finland, grant number 265940 (K.Ö.) and grant number 257545 (M.J.). Wihuri Research Institute is maintained by the Jenny and Antti Wihuri Foundation. Dr. Norbert Maier and Dr. Ning Gan are acknowledged for their help in the laboratory. Prof. Mauri Kostiainen is thanked for the coating material. T.F., J.S. and P.F. are also grateful to (i) the Swedish Knowledge Foundation for the KK HÖG 2014 project "SOMI (grant number 20140179) and for (ii) the Swedish Research Council (VR) project "Fundamental Studies on Molecular Interactions aimed at Preparative Separations and Biospecific Measurements” (grant number 2015-04627).

\section{Uncategorized References}

[1] J. Witos, J. Samuelsson, G. Cilpa-Karhu, J. Metso, M. Jauhiainen, M.-L. Riekkola, Partial filling affinity capillary electrophoresis including adsorption energy distribution calculations-towards reliable and feasible biomolecular interaction studies, Analyst, 140 (2015) 3175-3182.

[2] K. Lipponen, P.W. Stege, G. Cilpa, J.r. Samuelsson, T. Fornstedt, M.-L. Riekkola, Three different approaches for the clarification of the interactions between lipoproteins and chondroitin-6-sulfate, Analytical chemistry, 83 (2011) 6040-6046.

[3] G. Cilpa-Karhu, K. Lipponen, J. Samuelsson, K. Öörni, T. Fornstedt, M.-L. Riekkola, Three complementary techniques for the clarification of temperature effect on low-density lipoprotein-chondroitin-6-sulfate interaction, Analytical biochemistry, 443 (2013) 139-147.

[4] K. Lipponen, S. Tähkä, J. Samuelsson, M. Jauhiainen, J. Metso, G. Cilpa-Karhu, T. Fornstedt, M. Kostiainen, M.-L. Riekkola, Partial-filling affinity capillary electrophoresis and quartz crystal microbalance with adsorption energy distribution calculations in the study of biomolecular interactions with apolipoprotein $\mathrm{E}$ as interaction partner, Analytical and bioanalytical chemistry, 406 (2014) 4137-4146.

[5] R.L. Rich, D.G. Myszka, Survey of the year 2007 commercial optical biosensor literature, Journal of Molecular Recognition, 21 (2008) 355-400.

[6] M.S. Brown, P.T. Kovanen, J.L. Goldstein, Regulation of plasma cholesterol by lipoprotein receptors, Science, 212 (1981) 628-635.

[7] T. Hevonoja, M.O. Pentikäinen, M.T. Hyvönen, P.T. Kovanen, M. Ala-Korpela, Structure of low density lipoprotein (LDL) particles: basis for understanding molecular changes in modified LDL, Biochimica et Biophysica Acta (BBA)-Molecular and cell biology of lipids, 1488 (2000) 189-210.

[8] L. D’Ulivo, J. Saint-Guirons, B. Ingemarsson, M.-L. Riekkola, Quartz crystal microbalance, a valuable tool for elucidation of interactions between apoB-100 peptides and extracellular matrix components, Analytical and bioanalytical chemistry, 396 (2010) 1373-1380.

[9] J. Witos, J. Saint-Guirons, K. Meinander, L. D'Ulivo, M.-L. Riekkola, Collagen I and III and their decorin modified surfaces studied by atomic force microscopy and the elucidation of their affinity toward positive apolipoprotein B-100 residue by quartz crystal microbalance, Analyst, 136 (2011) 3777-3782.

[10] W.M. Haynes, CRC handbook of chemistry and physics, CRC press 2014. 
[11] R.M. Hnasko, L.H. Stanker, Hybridoma technology, ELISA: Methods and Protocols, (2015) 15-28.

[12] R.J. Havel, H.A. Eder, J.H. Bragdon, The distribution and chemical composition of ultracentrifugally separated lipoproteins in human serum, Journal of Clinical Investigation, 34 (1955) 1345.

[13] C.M. Radding, D. Steinberg, Studies on the synthesis and secretion of serum lipoproteins by rat liver slices, Journal of Clinical Investigation, 39 (1960) 1560.

[14] O.H. Lowry, N.J. Rosebrough, A.L. Farr, R.J. Randall, Protein measurement with the Folin phenol reagent, J biol Chem, 193 (1951) 265-275.

[15] G. Sauerbrey, Use of quartz vibration for weighing thin films on a microbalance, J. Physik, 155 (1959) 206212.

[16] J. Svitel, A. Balbo, R.A. Mariuzza, N.R. Gonzales, P. Schuck, Combined affinity and rate constant distributions of ligand populations from experimental surface binding kinetics and equilibria, Biophysical journal, 84 (2003) 4062-4077.

[17] D. Altschuh, H. Björkelund, J. Strandgård, L. Choulier, M. Malmqvist, K. Andersson, Deciphering complex protein interaction kinetics using Interaction Map, Biochemical and biophysical research communications, 428 (2012) 74-79.

[18] K. Lipponen, S. Tähkä, M. Kostiainen, M.L. Riekkola, Stable neutral double hydrophilic block copolymer capillary coating for capillary electrophoretic separations, Electrophoresis, 35 (2014) 1106-1113.

[19] B.A. Williams, G. Vigh, Fast, accurate mobility determination method for capillary electrophoresis, Analytical chemistry, 68 (1996) 1174-1180.

[20] A.-J. Wang, K. Vainikka, J. Witos, L. D’Ulivo, G. Cilpa, P.T. Kovanen, K. Öörni, M. Jauhiainen, M.-L. Riekkola, Partial filling affinity capillary electrophoresis with cationic poly (vinylpyrrolidone)-based copolymer coatings for studies on human lipoprotein-steroid interactions, Analytical biochemistry, 399 (2010) 93-101.

[21] N. Fang, H. Zhang, J. Li, H.-W. Li, E.S. Yeung, Mobility-based wall adsorption isotherms for comparing capillary electrophoresis with single-molecule observations, Analytical chemistry, 79 (2007) 6047-6054.

[22] D.D. Do, Adsorption Analysis: Equilibria and Kinetics:(With CD Containing Computer Matlab Programs), World Scientific1998.

[23] G. Guiochon, A. Felinger, D.G. Shirazi, Fundamentals of preparative and nonlinear chromatography, Academic Press2006.

[24] V.A. Hernández, J. Samuelsson, P. Forssén, T. Fornstedt, Enhanced interpretation of adsorption data generated by liquid chromatography and by modern biosensors, Journal of Chromatography A, 1317 (2013) 22 31.

[25] B.J. Stanley, G. Guiochon, Numerical estimation of adsorption energy distributions from adsorption isotherm data with the expectation-maximization method, The Journal of Physical Chemistry, 97 (1993) 80988104.

[26] H. Roos, R. Karlsson, H. Nilshans, A. Persson, Thermodynamic analysis of protein interactions with biosensor technology, Journal of Molecular Recognition, 11 (1998) 204-210.

[27] M. Guha, C. England, H. Herscovitz, O. Gursky, Thermal transitions in human very-low-density lipoprotein: fusion, rupture, and dissociation of HDL-like particles, Biochemistry, 46 (2007) 6043-6049. 


\section{FIGURES}


A

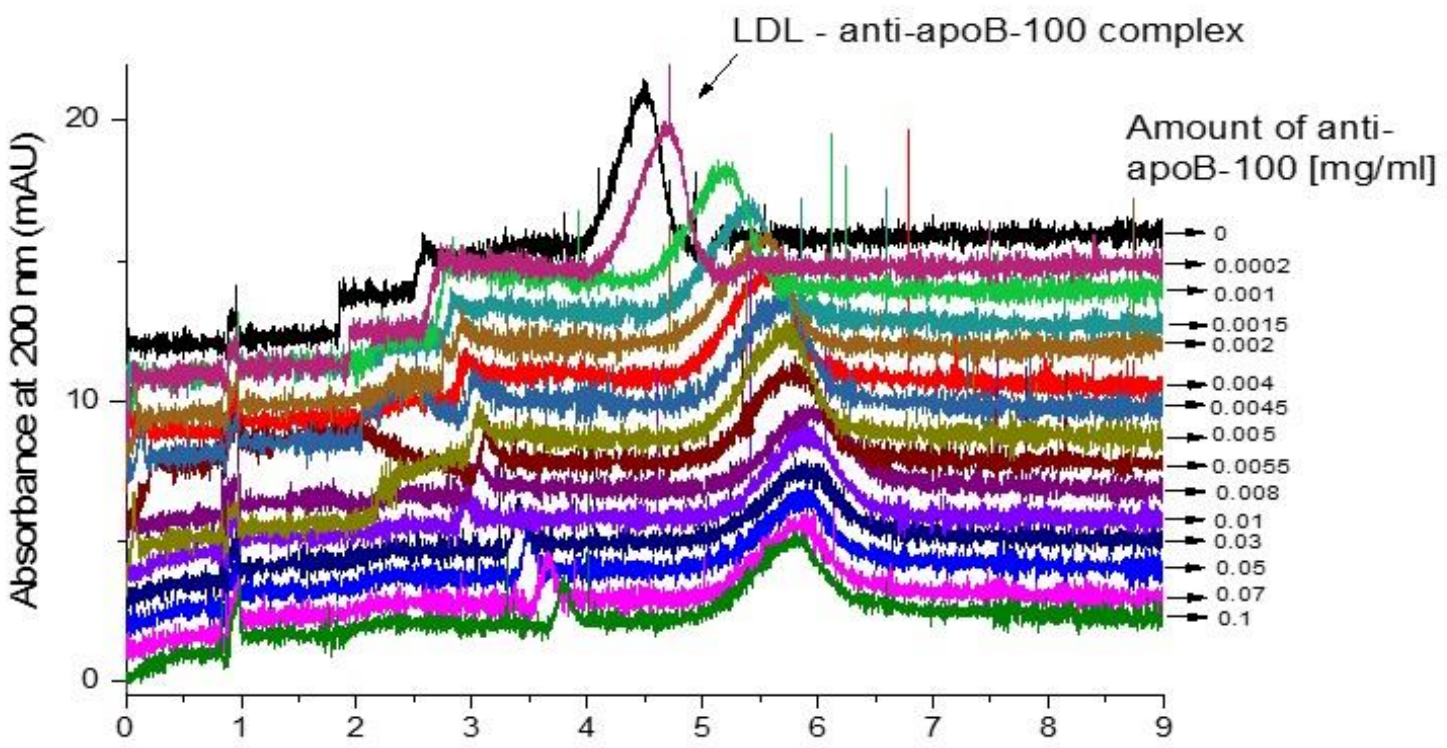

B

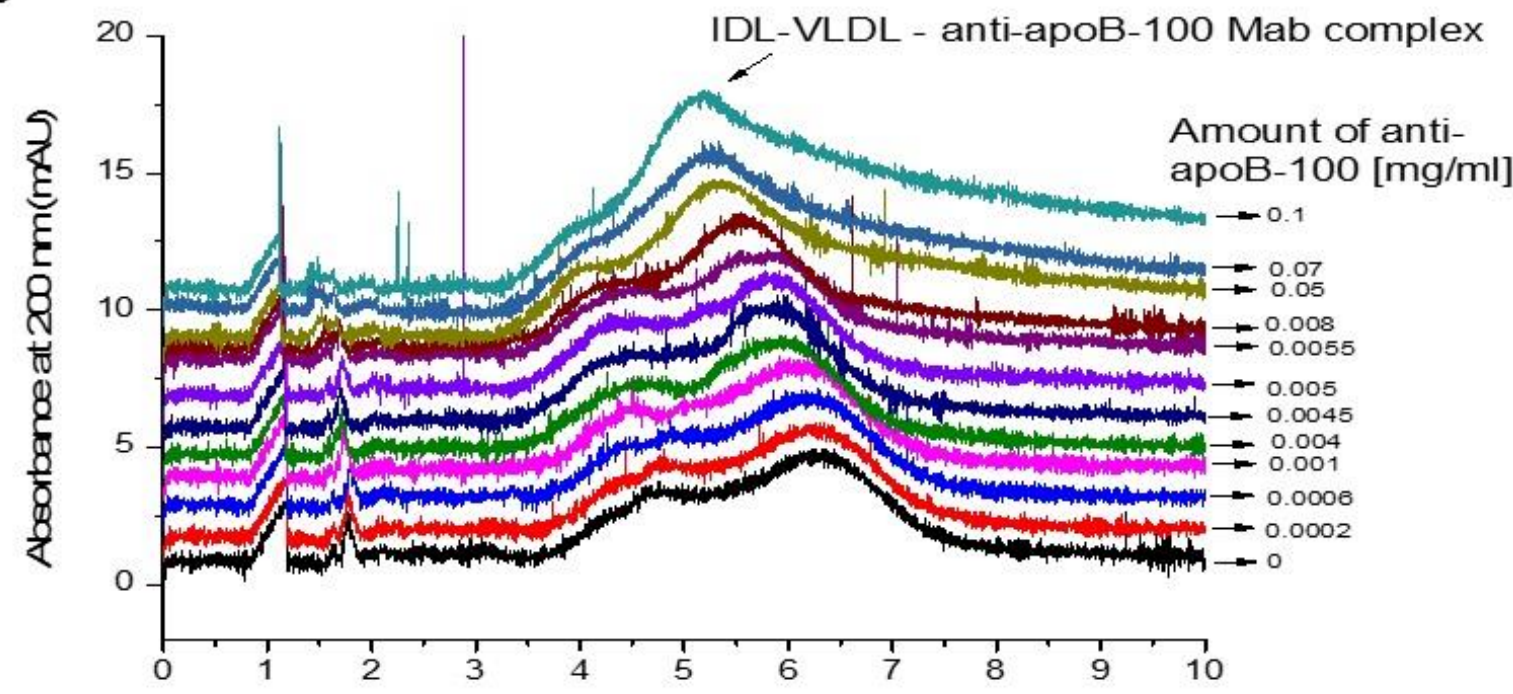

C

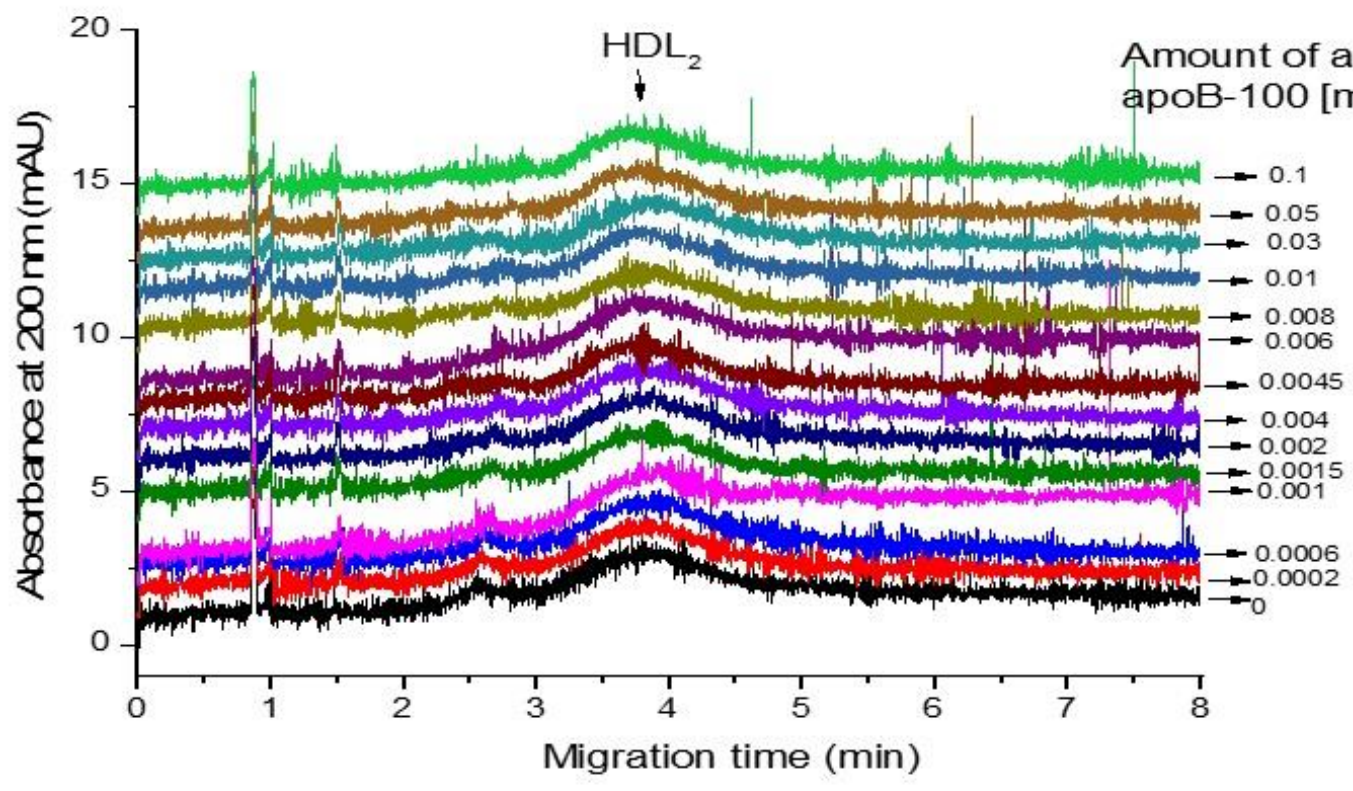


Figure 1. Partial filling affinity capillary electrophoresis electropherograms as a function of concentration of anti apoB-100 Mab interacting with (A) LDL; (B) IDL-VLDL; and (C) HDL2. Running conditions: $-25 \mathrm{kV}$, injection time of LDL $2 \mathrm{sec}$, IDL-VLDL $8 \mathrm{sec}$, and $\mathrm{HDL}_{2} 2 \mathrm{sec}$, all at 50 mbar, injection time of anti apoB-100 Mab was $3 \mathrm{sec}$ at $50 \mathrm{mbar}, 37^{\circ} \mathrm{C}, L_{\text {tot }} 38.5, L_{\mathrm{det}}$ $30 \mathrm{~cm}$, UV detection $200 \mathrm{~nm}$, BGE phosphate buffer (pH 7.4, I $20 \mathrm{mM}$ ), concentrations of LDL $0.075 \mathrm{mg} / \mathrm{ml}$, IDL-VLDL $0.036 \mathrm{mg} / \mathrm{ml}$, and $\mathrm{HDL}_{2} 0.2 \mathrm{mg} / \mathrm{ml}$, and anti-apoB-100 Mab concentration ranging from 0.00 to $0.10 \mathrm{mg} / \mathrm{ml}$.

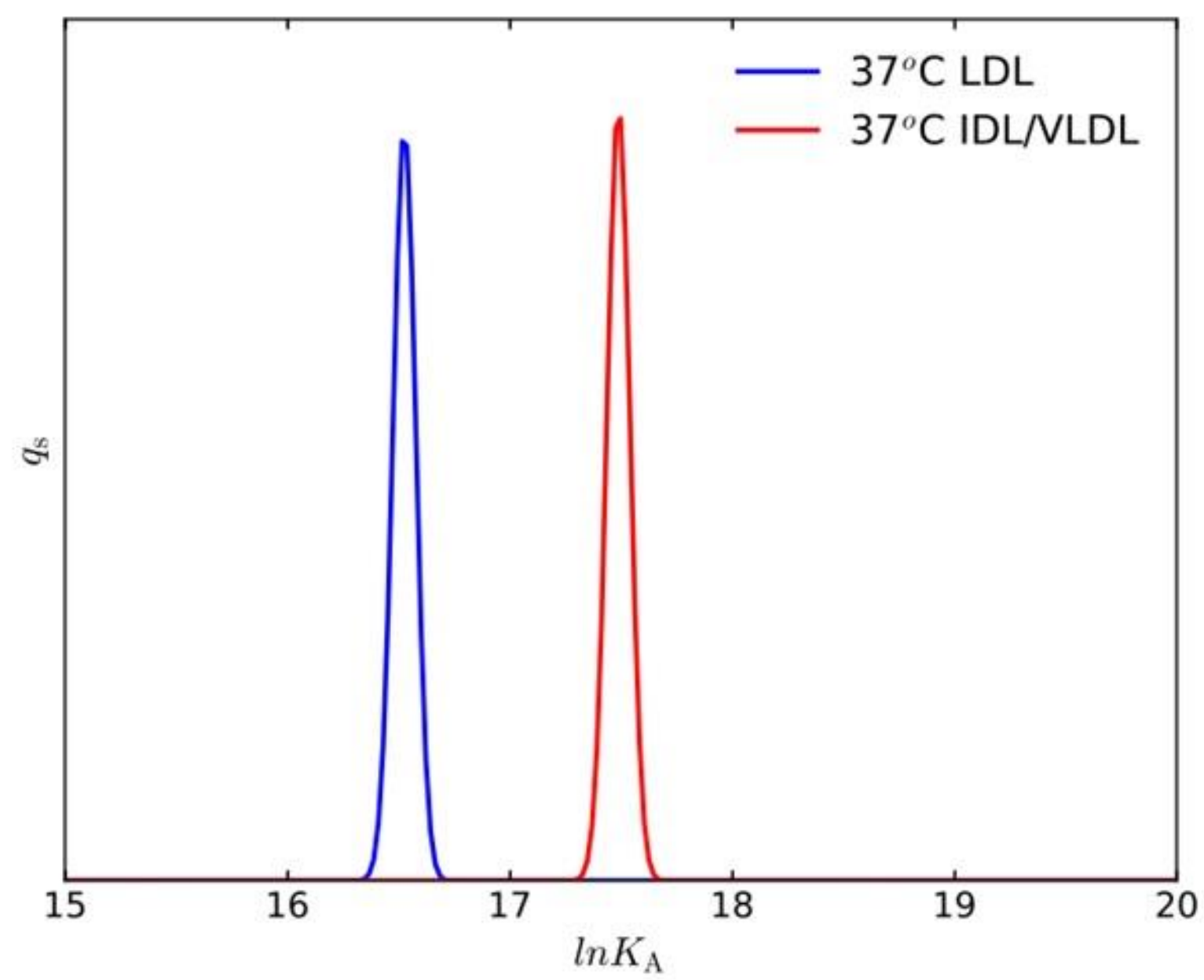

Figure 2. AED calculations for LDL, IDL-VLDL and anti-apoB-100 Mab systems at $37^{\circ} \mathrm{C}$. 

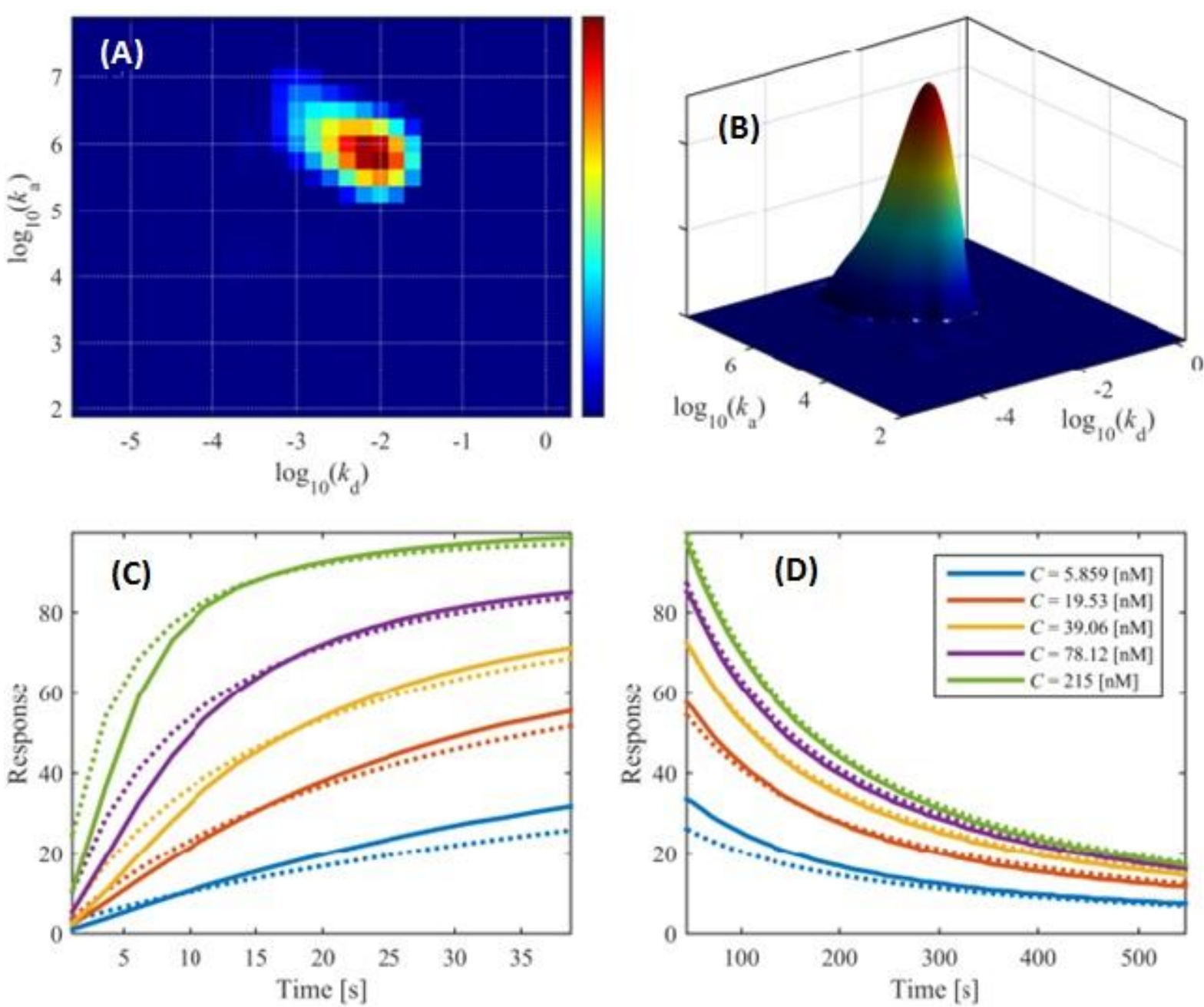

Figure 3. Interactions between LDL and anti-apoB-100 Mab at $37^{\circ} \mathrm{C}$ presented (A) and (B) as Interaction Maps, (C) as sensograms and model fits for association, and (D) as sensograms and model fits for dissociation. The dotted curves represent the model fitted sensograms and solid curves those obtained from the experimental data. 


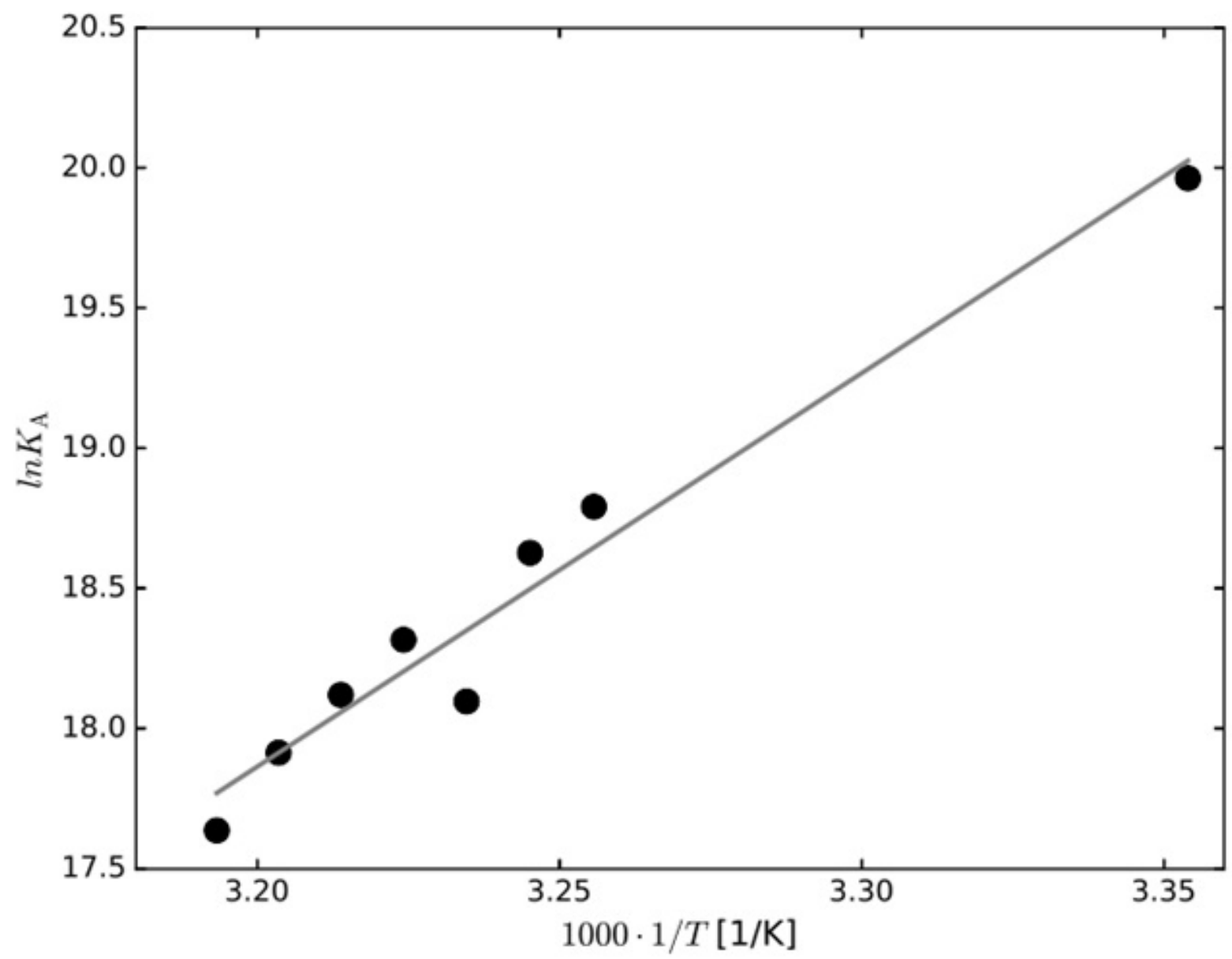

Figure 4. Van't Hoff plot for the interactions between LDL and anti-apoB-100 Mab. 

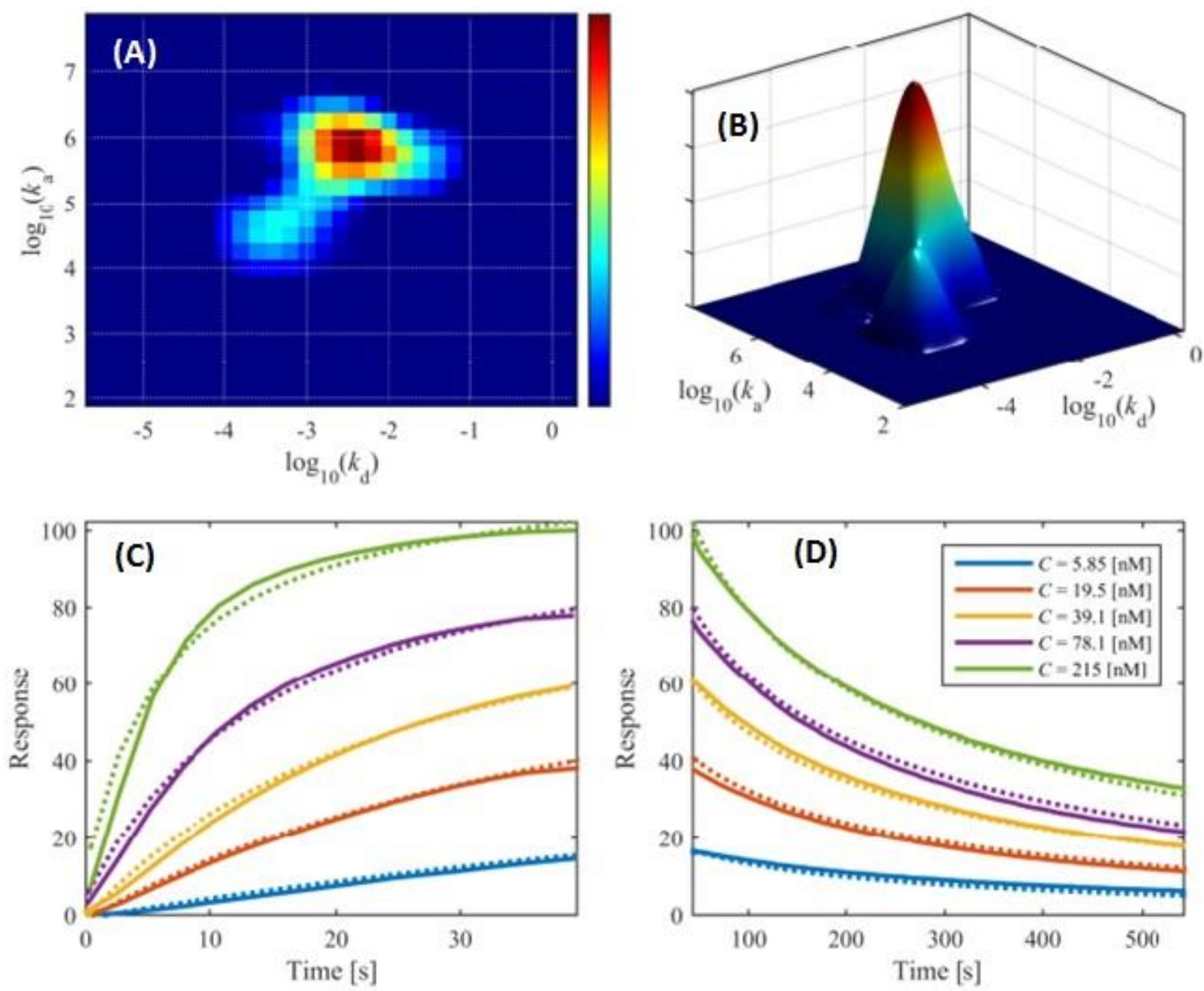

Figure 5. Interactions between IDL-VLDL and anti-apoB-100 Mab at $37^{\circ} \mathrm{C}$ presented (A) and (B) as Interaction Maps, (C) as sensograms and model fits for association, and (D) as sensograms and model fits for dissociation. The dotted curves represent the model fitted sensograms and solid curves those obtained from the experimental data. 


\section{TABLES}

Table 1. Effects of temperature- on kinetics and affinity data between anti-apoB-100 Mab and LDL obtained by QCM using Interaction Maps, and by PF-ACE using AED.

\begin{tabular}{|c|c|c|c|c|c|c|}
\hline System & $\begin{array}{l}\text { Temp. } \\
{\left[{ }^{\circ} \mathrm{C}\right]}\end{array}$ & $\begin{array}{c}K_{\mathrm{A}} \\
{\left[\mathbf{M}^{-1}\right]}\end{array}$ & $\log K_{A}$ & $\begin{array}{c}K_{\mathrm{D}} \\
{[\mathrm{nM}]}\end{array}$ & $\begin{array}{c}k_{\mathrm{a}} \\
{\left[\mathbf{M}^{-1} \mathbf{s}^{-1}\right]}\end{array}$ & $\begin{array}{c}k_{\mathrm{d}} \\
{\left[\mathrm{s}^{-1}\right]}\end{array}$ \\
\hline \multirow[t]{8}{*}{ QCM } & 25 & $4.68 \cdot 10^{8}$ & 8.67 & 2.14 & $8.13 \cdot 10^{5}$ & $1.74 \cdot 10^{-3}$ \\
\hline & 34 & $1.45 \cdot 10^{8}$ & 8.16 & 6.92 & $7.76 \cdot 10^{5}$ & $5.37 \cdot 10^{-3}$ \\
\hline & 35 & $1.23 \cdot 10^{8}$ & 8.09 & 8.13 & $7.94 \cdot 10^{5}$ & $6.46 \cdot 10^{-3}$ \\
\hline & 36 & $7.24 \cdot 10^{7}$ & 7.86 & 13.80 & $6.92 \cdot 10^{5}$ & $9.55 \cdot 10^{-3}$ \\
\hline & 37 & $9.02 \cdot 10^{7}$ & 7.96 & 11.09 & $8.61 \cdot 10^{5}$ & $9.55 \cdot 10^{-3}$ \\
\hline & 38 & $7.41 \cdot 10^{7}$ & 7.87 & 13.49 & $9.12 \cdot 10^{5}$ & $1.23 \cdot 10^{-2}$ \\
\hline & 39 & $6.03 \cdot 10^{7}$ & 7.78 & 16.60 & $8.51 \cdot 10^{5}$ & $1.41 \cdot 10^{-2}$ \\
\hline & 40 & $4.57 \cdot 10^{7}$ & 7.66 & 21.88 & $8.32 \cdot 10^{5}$ & $1.82 \cdot 10^{-2}$ \\
\hline $\mathbf{C E}$ & 37 & $2.54 \cdot 10^{7}$ & 7.41 & 39.37 & ND & ND \\
\hline
\end{tabular}


Table 2. The effect of temperature on the derived thermodynamic state functions for the interaction of LDL and anti-apoB-100 Mab measured by QCM.

\begin{tabular}{cccc}
\hline Temp. $\left[{ }^{\mathbf{0}} \mathbf{C}\right]$ & $\begin{array}{c}\Delta \mathbf{G}^{\mathbf{0}} \\
{\left[\mathbf{k J} \mathbf{~ m o l}^{-1}\right]}\end{array}$ & $\begin{array}{c}\Delta \mathbf{H}^{\mathbf{0}} \\
{\left[\mathbf{k J} \mathbf{~ m o l}^{-\mathbf{1}}\right]}\end{array}$ & $\begin{array}{c}\Delta \mathbf{S}^{\mathbf{0}} \\
{\left[\mathbf{J} \cdot \mathbf{K}^{-1} \mathbf{~ m o l}^{-\mathbf{1}}\right]}\end{array}$ \\
\hline 25 & -49.5 & -116.7 & -225.0 \\
34 & -48.0 & -116.7 & -225.0 \\
35 & -47.7 & -116.7 & -225.0 \\
36 & -46.5 & -116.7 & -225.0 \\
38 & -47.2 & -116.7 & -225.0 \\
39 & -46.9 & -116.7 & -225.0 \\
40 & -46.5 & -116.7 & -225.0 \\
& -45.9 & -116.7 & -225.0 \\
& & &
\end{tabular}


Table 3. Kinetics and affinity data between anti-apoB-100 Mab and IDL-VLDL obtained by QCM using Interaction Maps, and PF-ACE using AED.

\begin{tabular}{|c|c|c|c|c|c|c|c|c|c|c|c|}
\hline System & $\begin{array}{l}\text { Temp. } \\
{\left[{ }^{\circ} \mathrm{C}\right]}\end{array}$ & $\begin{array}{c}K_{\mathbf{A}, 1} \\
{\left[\mathbf{M}^{-1}\right]}\end{array}$ & $\begin{array}{l}\log \\
K_{A, I}\end{array}$ & $\begin{array}{c}K_{\mathbf{D}, 1} \\
{[\mathbf{n M}]}\end{array}$ & $\begin{array}{c}\boldsymbol{k}_{\mathrm{a}, 1} \\
{\left[\mathbf{M}^{-1} \mathbf{s}^{-1}\right]}\end{array}$ & $\begin{array}{l}k_{\mathrm{d}, 1} \\
{\left[\mathbf{s}^{-1}\right]}\end{array}$ & $\begin{array}{c}K_{\mathrm{A}, 2} \\
{\left[\mathbf{M}^{-1}\right]}\end{array}$ & $\begin{array}{l}\log \\
K_{A, 2}\end{array}$ & $\begin{array}{c}K_{\mathbf{D}, 2} \\
{[\mathrm{nM}]}\end{array}$ & $\begin{array}{c}\boldsymbol{k}_{\mathrm{a}, 2} \\
{\left[\mathbf{M}^{-1} \mathbf{s}^{-1}\right]}\end{array}$ & $\begin{array}{l}k_{\mathrm{d}, 2} \\
{\left[\mathbf{s}^{-1}\right]}\end{array}$ \\
\hline QCM & 37 & $1.00 \cdot 10^{8}$ & 8.00 & 10.00 & $5.54 \cdot 10^{5}$ & $5.54 \cdot 10^{-3}$ & $6.38 \cdot 10^{7}$ & 7.80 & 15.67 & $5.15 \cdot 10^{4}$ & $8.07 \cdot 10^{-4}$ \\
\hline $\mathrm{CE}$ & 37 & $4.94 \cdot 10^{7}$ & 7.69 & 20.24 & ND & ND & ND & ND & ND & ND & ND \\
\hline
\end{tabular}

ND, not determined. Subscripts 1 and 2, represent sites 1 and 2. $\mathrm{K}_{\mathrm{A}}$, affinity constant. $\mathrm{K}_{\mathrm{D}}$, dissociation constant. $\mathrm{k}_{\mathrm{a}}$, association rate constant. $\mathrm{k}_{\mathrm{d}}$, dissociation rate constant. 